\title{
Diferentes suplementos no cultivo in vitro de embriões de pinhão-manso
}

\author{
Claudinéia Ferreira Nunes ${ }^{(1)}$, Moacir Pasqual(1), Dalilhia Nazaré dos Santos ${ }^{(1)}$, Telde Natel Custódio(1) \\ e Aparecida Gomes de Araujo(1)
}

\begin{abstract}
(1)Universidade Federal de Lavras, Departamento de Agricultura, Caixa Postal 37, CEP 37200-000 Lavras, MG. E-mail: nunescfr@yahoo.com.br, mpasqual@ufla.br, dalilhia@yahoo.com.br, telde@uflanet.com.br, agaraujo2003@hotmail.com
\end{abstract}

\begin{abstract}
Resumo - O objetivo deste trabalho foi avaliar a influência do estádio de maturação dos frutos, no desenvolvimento de embriões de pinhão-manso (Jatropha curcas), cultivados em meio MS com diferentes suplementos: sacarose, água de coco e carvão ativado. Os frutos foram coletados, e os embriões de suas sementes extraídos assepticamente. Utilizaram-se duas condições experimentais: embriões oriundos de frutos em três estádios de desenvolvimento (imaturo, maduro e seco), colocados em meio de cultivo MS acrescido de sacarose $(0,15,30 \mathrm{e}$ $60 \mathrm{~g} \mathrm{~L}^{-1}$ ); embriões oriundos de frutos secos, colocados em meio MS acrescido de: $30 \mathrm{~g} \mathrm{~L}^{-1}$ de sacarose, carvão ativado $\left(0,1,2\right.$ e $\left.3 \mathrm{~g} \mathrm{~L}^{-1}\right)$ e de água de coco $\left(0,50,100,150,200 \mathrm{e} 250 \mathrm{~mL} \mathrm{~L}^{-1}\right)$. O material foi mantido por 30 dias em sala de crescimento, sob condições ambientais controladas. Apenas os embriões zigóticos provenientes de frutos imaturos necessitam da suplementação de sacarose para sustentar sua germinação. O melhor desenvolvimento de embriões ocorre em meio MS suplementado com $60 \mathrm{~g} \mathrm{~L}^{-1}$ de sacarose. A associação de carvão ativado e água de coco proporcionam melhor crescimento de plântulas oriundas de embriões de sementes retiradas de frutos secos.
\end{abstract}

Termos para indexação: Jatropha curcas, água de coco, carvão ativado, cultura de tecidos, sacarose.

\section{Different supplements for in vitro embryo culture of physic nut}

\begin{abstract}
The objective of this work was to evaluate the influence of maturation stages of physic nut fruits on the development of their embryos cultivated in MS medium supplemented with sucrose, coconut water and activated carbon. Fruits were collected, and their embryos were extracted aseptically. They were submitted to two experimental conditions: embryos from fruits in three development stages (immature, mature and dry) were put into MS medium, supplemented with sucrose $\left(0,15,30\right.$ and $\left.60 \mathrm{~g} \mathrm{~L}^{-1}\right)$; embryos derived from dry fruits were put into MS medium supplemented with sucrose $30 \mathrm{~g} \mathrm{~L}^{-1}$, activated carbon $\left(0,1,2\right.$ and $\left.3 \mathrm{~g} \mathrm{~L}^{-1}\right)$, and coconut water $(0$, 50, 100, 150, 200 e $250 \mathrm{~mL} \mathrm{~L}^{-1}$ ). Explants were kept in a growth chamber under controlled conditions during 30 days. Only the zygotic embryos from immature fruits needed sucrose supplementation in the culture medium to sustain germination. Better embryos development occurs in MS medium supplemented with $60 \mathrm{~g} \mathrm{~L}^{-1}$ of sucrose. The association of activated carbon and coconut water provides better growth of seedlings derived from embryos extracted from seeds of dry fruits.
\end{abstract}

Index terms: Jatropha curcas, coconut water, activated carbon, tissue culture, sucrose.

\section{Introdução}

Óleos vegetais provenientes de diversas oleaginosas têm sido testados com sucesso na produção de biodiesel. A espécie Jatropha curcas L. é considerada promissora por seu elevado teor de óleo (25 a 40\%), superior ao da maioria das oleaginosas utilizadas no mercado de biocombustíveis (Arruda et al., 2004).

O pinhão-manso é de fácil cultivo, e seu óleo tem variações pouco significativas de acidez, além de possuir melhor estabilidade à oxidação do que a soja e a palma, e boa viscosidade se comparado ao da mamona (Tapanes et al., 2007)

A espécie se propaga por via seminal e vegetativa (Saturnino et al., 2005). Plantios desuniformes, com uso de sementes, e a baixa demanda de material vegetal (estacas) têm sido apontados como os principais fatores que limitam a expansão da cultura. Assim, pesquisas a respeito de multiplicação in vitro da espécie são imprescindíveis. 
Estudos de suplementação dos meios de cultura com fontes exógenas de carboidratos e outros aditivos, que favoreçam a germinação in vitro de J. curcas, são importantes tanto para maximizar a taxa de germinação dessa espécie quanto para obter plântulas com elevado potencial fisiológico para serem utilizadas como fonte de explante, em estudos sobre embriogênese somática ou organogênese. Para várias espécies perenes, inclusive algumas da família Euphorbiaceae, como Jatropha podagrica (Jesus et al., 2003), foi possível estabelecer protocolos de germinação in vitro de embriões zigóticos.

Em estudos realizados por Spera (1995), com embriões de J. podagrica, verificou-se que concentrações de sacarose de até $30 \mathrm{~g} \mathrm{~L}^{-1}$ foram suficientes para o bom crescimento das plântulas. Outros estudos com diferentes espécies apontam que a utilização de água de coco e carvão ativado, em suplementação ao meio de cultura, é requerida para suprir as exigências nutricionais e fisiológicas dos embriões (Ribeiro et al., 2000; Carvalho et al., 2003; Chagas et al., 2005).

A água de coco fornece açúcares e outros metabólitos para embriões cultivados in vitro; vários trabalhos citam sua utilização no cultivo in vitro de espécies perenes, como os de Ferreira et al. (2004) sobre o cupuaçu, e Latado et al. (1999) sobre citros. O carvão ativado, quando adicionado ao meio de cultura, possui a capacidade de adsorver substâncias tóxicas liberadas pelos explantes ou impurezas de outros componentes (Grattapaglia \& Machado, 1998).

Como o número de trabalhos publicados com cultura de tecidos de $J$. curcas é bastante restrito, e é crescente a importância econômica dessa espécie, o objetivo deste trabalho foi avaliar a influência do estádio de maturação de seus frutos no desenvolvimento de embriões cultivados em meio MS acrescido de diferentes suplementos.

\section{Material e Métodos}

Foram utilizados, como fonte de embriões, frutos nos estádios imaturo, maduro e seco coletados de plantas adultas de $J$. curcas, da safra de 2006, provenientes do Município de Janaúba, MG.

As sementes retiradas dos frutos tiveram o invólucro exterior (casca) removido, e foram submetidas à assepsia pela imersão em água destilada, com duas gotas de detergente comercial por $1 \mathrm{~min}$, em álcool $70 \% \mathrm{v} / \mathrm{v}$ por 1 min e em hipoclorito de sódio $1 \% \mathrm{v} / \mathrm{v}$ por $20 \mathrm{~min}$, sob agitação constante. Os agentes desinfestantes foram removidos com tríplice lavagem em água destilada estéril.

Posteriormente, em câmara de fluxo laminar, os tegumentos das sementes foram separados longitudinalmente pela região oposta à micrópila. Os embriões excisados foram colocados, individualmente, em tubos de ensaio de $25 \times 150 \mathrm{~mm}$, com $15 \mathrm{~mL}$ do meio de cultivo MS (Murashige \& Skoog, 1962) modificado de acordo com cada experimento.

Os embriões excisados foram submetidos a dois experimentos. No experimento 1, os embriões (fase torpedo ou cotiledonar) foram retirados de frutos, em diferentes estádios fisiológicos de maturação (imaturo, maduro e seco), e foram colocados em meio MS acrescido de sacarose $\left(0,15,30\right.$ e $\left.60 \mathrm{~g} \mathrm{~L}^{-1}\right)$, em todas as combinações possíveis. Foi utilizado o delineamento inteiramente casualizado, em esquema fatorial $4 \times 3$, com quatro repetições de três tubos cada uma. Frutos imaturos caracterizavam-se pela coloração externa verde-cana do epicarpo, verde-claro do mesocarpo, semente esbranquiçada, pouco resistente, endosperma pouco consistente e não completamente desenvolvido. Os frutos maduros apresentavam o epicarpo com coloração externa marrom-escura, mesocarpo esverdeado, semente de coloração marrom-intensa, bastante resistente, e endosperma bem desenvolvido. Os frutos secos apresentavam o epicarpo de coloração preta e em fase de deiscência, mesocarpo seco e sementes de coloração preta, com presença de estrias. No experimento 2, os embriões (fase cotiledonar) provenientes de frutos secos foram colocados em meio MS, suplementado com $30 \mathrm{~g} \mathrm{~L}^{-1}$ de sacarose e carvão ativado $\left(0,1,2\right.$, e $\left.3 \mathrm{~g} \mathrm{~L}^{-1}\right)$ combinado com água de coco comercial $(0,50,100,150$, 200 e $250 \mathrm{~mL} \mathrm{~L}^{-1}$ ). O delineamento experimental foi inteiramente casualizado, em ensaio fatorial $6 \times 4$, constituído de quatro repetições com três tubos cada uma.

Nos dois experimentos, os meios de cultivo foram solidificados com $6 \mathrm{~g} \mathrm{~L}^{-1}$ de ágar, com $\mathrm{pH}$ ajustado para 5,8, antes da autoclavagem a $121^{\circ} \mathrm{C}$ por $20 \mathrm{~min}$. As culturas foram mantidas em sala de crescimento a $27 \pm 1^{\circ} \mathrm{C}$, irradiância de $35 \mu \mathrm{mol} \mathrm{m}{ }^{-2} \mathrm{~s}^{-1}$, fornecida por lâmpadas fluorescentes brancas de $20 \mathrm{~W}$ e fotoperíodo de 16 horas.

Após 30 dias, as plântulas de ambos os experimentos foram avaliadas, com base nas seguintes variáveis: percentagem de embriões germinados, comprimento da parte aérea, número de folhas, número de raízes e comprimento do sistema radicular.

Os dados foram submetidos à análise de variância pelo teste $\mathrm{F}$ a $5 \%$ de probabilidade, e quando as diferenças 
entre os tratamentos foram significativas, utilizou-se o ajustamento a modelos de superfície de resposta (Box \& Draper, 1987). As médias de fator quantitativo foram comparadas por regressão polinomial, e as de fator qualitativo pelo teste de Tukey a $5 \%$ de probabilidade. O programa utilizado para as análises estatísticas foi o Statistics Analysis System (SAS Institute, 1998).
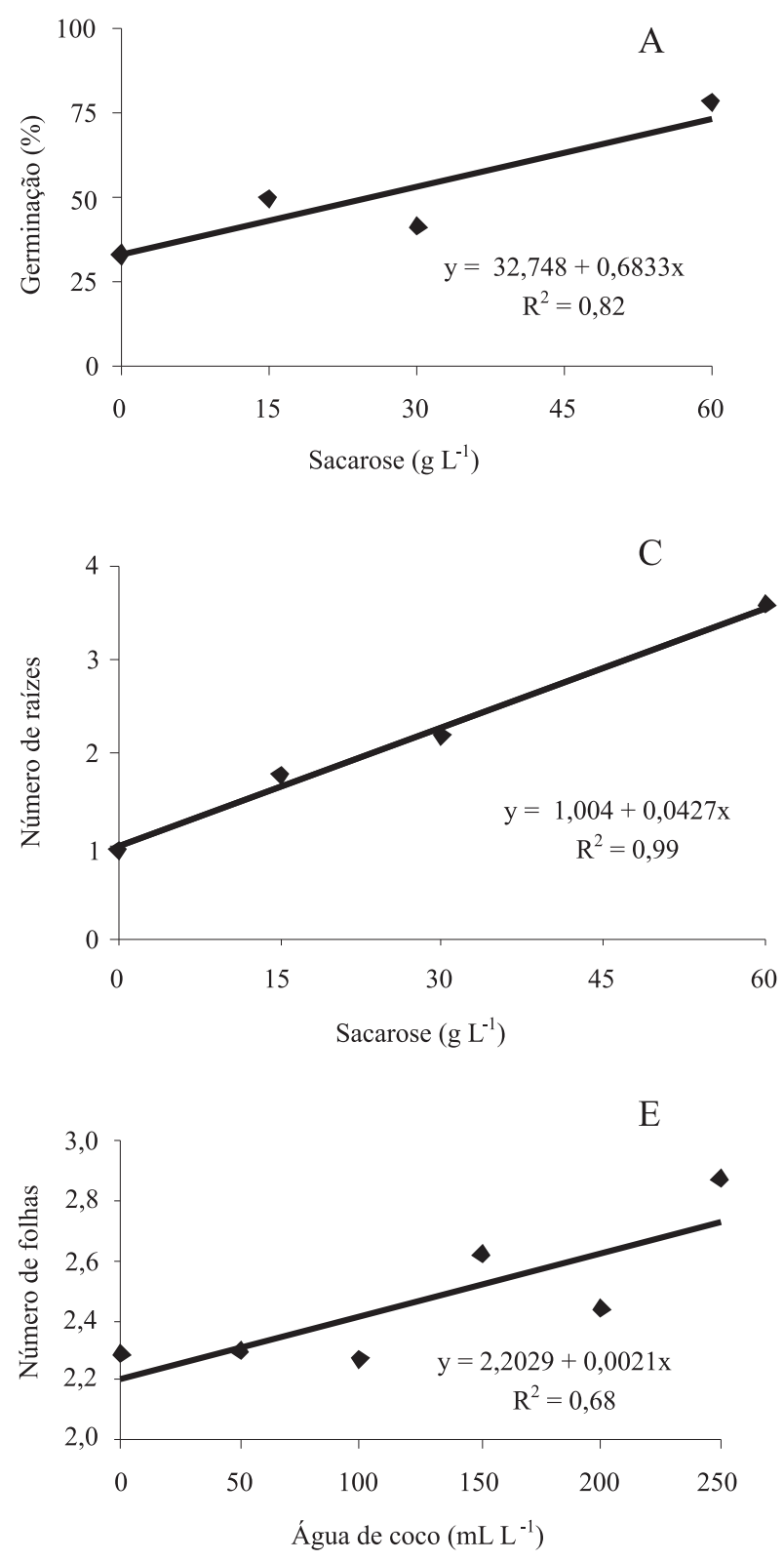

\section{Resultados e Discussão}

A maior concentração de sacarose maximizou a percentagem de germinação dos embriões oriundos de fruto imaturo (Figura 1 A) e não foi significativa para os de estádios maduro e seco. A percentagem de germinação, para embriões (fase torpedo) provenientes
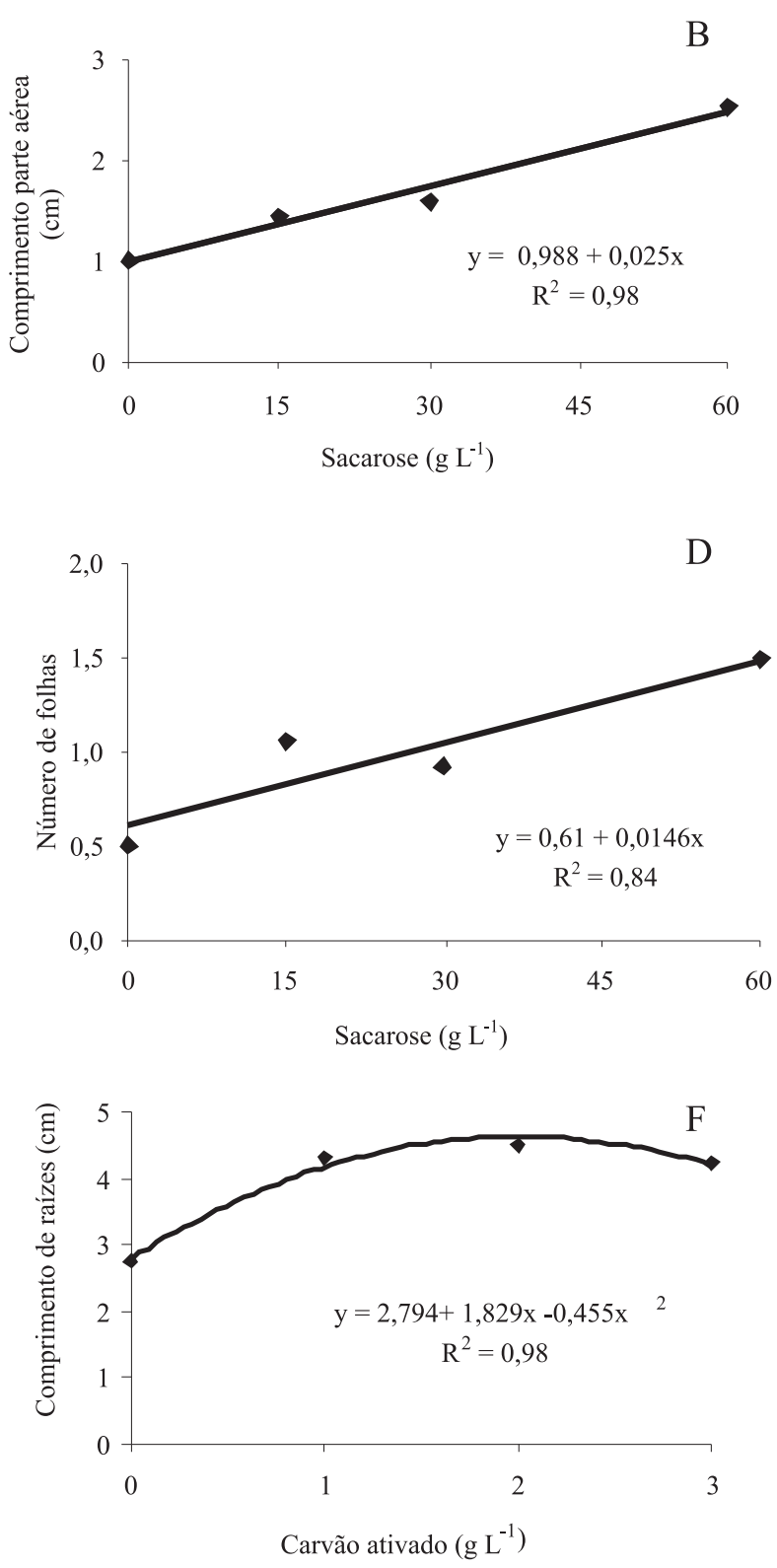

Figura 1. Percentagem de germinação em embriões oriundos de frutos imaturos, cultivados em meio MS com diferentes concentrações de sacarose (A); comprimento da parte aérea (B); número de raízes (C); número de folhas em embriões oriundos de frutos secos, cultivados em meio MS com diferentes concentrações de sacarose (D); número de folhas em plântulas, em função da concentração de água de coco (E); e comprimento de raízes, em função da concentração de carvão ativado, no cultivo in vitro de embriões cotiledonares $(\mathrm{F})$. 
de frutos imaturos, cresceu linearmente com as concentrações de sacarose. A maior percentagem correspondeu à concentração de $60 \mathrm{~g} \mathrm{~L}^{-1}$ de sacarose e contribuiu com $83,68 \%$ de embriões germinados. A adição de sacarose no meio para cultura de embriões tem sido observada por vários autores, em diferentes espécies de plantas (Hu \& Ferreira, 1998; Torres et al., 2005), principalmente para embriões nos estádios iniciais de desenvolvimento (pró-embriões). De modo geral, quanto mais jovens os embriões, tanto maior será a osmolaridade requerida para o meio (Hu \& Ferreira, 1998).

A ausência de resposta de embriões, oriundos de frutos maduros e secos de J.curcas, ao aumento nas concentrações de sacarose, revela que o processo de germinação para esses embriões ocorre em razão das reservas nutricionais dos cotilédones, presentes nos embriões excisados, e das fontes nutricionais presentes no meio de cultura, que o tornam independente do fornecimento de sacarose. Garcia et al. (2002) relatam esses resultados e afirmam que, a depender da espécie e do estádio de desenvolvimento dos embriões, a presença de carboidratos no meio de cultura pode ser em concentrações mínimas ou até dispensável.

Quanto ao estádio fisiológico do fruto, os melhores resultados para comprimento da parte aérea e número de raízes foram observados quando se utilizaram embriões provenientes de frutos no estádio seco (fase cotiledonar). Também, para a característica número de folhas, embriões nesse estádio apresentaram média superior ao estádio de fruto imaturo, porém não diferiram significativamente dos embriões oriundos de frutos nos estádios maduro e seco (Tabela 1). Esses resultados estão de acordo com os encontrados por Pereira et al. (2006), que observaram que embriões de murmuru (Astrocaryum ulei), oriundos de frutos maduros, apresentaram maior crescimento in vitro, quando comparados aos embriões oriundos de frutos imaturos.

Tabela 1. Comprimento da parte aérea (CPA), número de raízes (NR) e de folhas (NF) em plântulas de Jatropha curcas, provenientes de embriões extraídos de diferentes estádios de desenvolvimento do fruto e cultivados em meio MS, independentemente da concentração de sacarose ${ }^{(1)}$.

\begin{tabular}{lccc}
\hline Estádio do fruto & CPA $(\mathrm{cm})$ & NR & NF \\
\hline Imaturo & $0,51 \mathrm{c}$ & $1,06 \mathrm{~b}$ & $0,54 \mathrm{~b}$ \\
Maduro & $1,77 \mathrm{~b}$ & $1,98 \mathrm{~b}$ & $0,89 \mathrm{ab}$ \\
Seco & $2,65 \mathrm{a}$ & $3,33 \mathrm{a}$ & $1,53 \mathrm{a}$ \\
\hline
\end{tabular}

${ }^{(1)}$ Médias seguidas de letras iguais, na coluna, não diferem entre si pelo teste de Tukey, a $5 \%$ de probabilidade.
O aumento das concentrações de sacarose no meio de cultura proporcionou crescimento linear do comprimento da parte aérea das plântulas (Figura $1 \mathrm{~B}$ ), independentemente do estádio em que os embriões foram excisados. Esse resultado difere do obtido por Spera (1995), em que diferentes concentrações de sacarose foram avaliadas, e a maior altura de plântulas de $J$. podagrica foi obtida quando se utilizou a concentração de $30 \mathrm{~g} \mathrm{~L}^{-1}$, além disso, concentrações maiores promoveram diminuição da altura das plântulas. Essa diferença de resultados poderia ser explicada pelo fator genético, por se tratar de duas espécies distintas.

Os melhores resultados quanto ao número de raízes e folhas foram verificados, também, com a maior concentração de sacarose testada (Figura $1 \mathrm{C}$ e D), o que corrobora os de Skrebsky et al. (2004), em trabalho realizado com ginseng brasileiro (Pfaffia glomerata), em que obtiveram maior número de raízes na presença de concentrações entre 45 e $60 \mathrm{~g} \mathrm{~L}^{-1}$ de sacarose.

Teores elevados de sacarose podem inibir a síntese de clorofila nas espécies cultivadas (Rodrigues et al., 2006). A sacarose no meio de cultivo in vitro influencia vários processos metabólicos nas culturas e apresenta efeito sobre o crescimento e diferenciação dos tecidos, além de manter a osmolaridade adequada com a fase de desenvolvimento do embrião (Skrebsky et al., 2004).

De modo geral, os melhores resultados em todas as variáveis analisadas foram obtidos com o aumento das concentrações de sacarose no meio de cultura até a concentração máxima de $60 \mathrm{~g} \mathrm{~L}^{-1}$, independentemente do estádio de maturação do embrião.

A adição de água de coco e carvão ativado ao meio de cultura não influenciou o percentual de germinação de embriões cotiledonares, com média de $81 \%$. No entanto, Spera (1995), ao estudar a propagação in vitro de J. podagrica, obteve maior índice de velocidade de germinação (IVG) com a adição de carvão ativado no meio de cultura. Pinheiro et al. (2001) observaram que a suplementação do meio com água de coco limitou a germinação in vitro de mangabeira (Hancornia speciosa). A alta disponibilidade de macro e micronutrientes, vitaminas e aminoácidos no meio básico MS, em comparação a outros meios de cultura, poderia justificar as elevadas taxas de germinação apresentadas, independentemente da presença de água de coco ou carvão ativado.

Verificou-se aumento linear do número de folhas por plântula, em relação a concentrações crescentes de água de coco, independentemente da suplementação com 
carvão ativado (Figura 1 E). O efeito estimulatório da água de coco pode ser explicado pelos elevados teores de glicose, frutose e sais minerais, além de hormônios vegetais, necessários ao processo de formação e desenvolvimento de plântulas. No entanto, o efeito da concentração de água de coco, no meio de cultura, parece estar relacionado também ao genótipo em questão. Por exemplo, Carvalho et al. (2003) constataram que o sucesso da regeneração de embriões imaturos de algodoeiro (Gossypium hirsutum) foi obtido em meio suplementado com $10 \%$ de água de coco.

O comprimento máximo de raízes foi observado com o aumento das concentrações de carvão ativado até $2 \mathrm{~g} \mathrm{~L}^{-1}$, com redução em concentrações superiores (Figura $1 \mathrm{~F}$ ). Tal comportamento, provavelmente, se deve ao fato de que a condição de escuro, proporcionada pelo carvão ativado, permite o alongamento das raízes, que vão em busca de luz. Fisicamente, ocorre simulação da condição de escuro, em que as raízes normalmente se desenvolvem melhor pela redução da incidência de luz na zona de crescimento ativo do sistema radicular (Ledo et al., 2007). Os resultados obtidos neste trabalho confirmam a hipótese de que a adição de carvão ativado no meio de cultura pode promover ou inibir o crescimento in vitro, a depender da concentração utilizada (Pan \& Staden, 1998).

Os efeitos da interação de água de coco e carvão ativado sobre o comprimento da parte aérea podem ser observados na Figura 2. Nota-se que as respostas foram de natureza

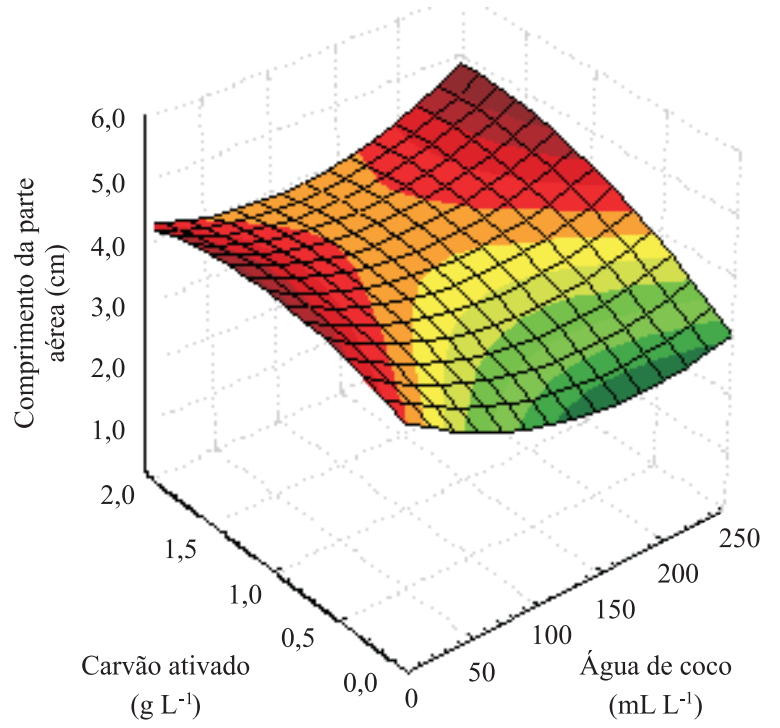

Figura 2. Comprimento da parte aérea de plântulas de Jatropha curcas, submetidas a diferentes concentrações de água de coco e carvão ativado. quadrática, em que a maximização do comprimento da parte aérea foi obtida com a concentração intermediária de água de coco (entre 100 e $150 \mathrm{~mL} \mathrm{~L}^{-1}$ ), combinada com carvão ativado (entre 1,5 e $2 \mathrm{~g} \mathrm{~L}^{-1}$ ). Segundo o modelo de superfície de resposta ajustado $-[\mathrm{CPA}=4,1093-0,0152 \mathrm{CAC}+$ $1,1087 \mathrm{CAT}+0,00004 \mathrm{CAC}^{2}-0,4892 \mathrm{CAT}^{2}+0,0031 \mathrm{CAC}$ $\times \mathrm{CAT}]\left(\mathrm{R}^{2}=0,41\right)$, em que: CPA é o comprimento da parte aérea $(\mathrm{cm})$; CAC é a concentração de água de coco ( $\left.\mathrm{mL} \mathrm{L}^{-1}\right)$; e CAT é a concentração de carvão ativado $\left(\mathrm{g} \mathrm{L}^{-1}\right)$-, a resposta máxima seria obtida com uma concentração de 125,84 $\mathrm{mL} \mathrm{L}^{-1}$ de água de coco e 1,54 g L-1 de carvão ativado, para obtenção de um comprimento médio de $4,03 \mathrm{~cm}$ por plântula.

Devido à eficiência do carvão ativado em adsorver substâncias indesejáveis que eventualmente estão presentes no meio de cultivo, supõe-se que algum componente inibitório ao cultivo dos embriões tenha sido adsorvido pelo carvão ativado, em auxílio ao desenvolvimento in vitro dos embriões da espécie estudada. Os resultados apresentados neste trabalho corroboram os de Ribeiro et al. (2000) e Chagas et al. (2005), com diversas espécies de citros, em que registraram que o suprimento adequado de carvão ativado é requisito importante para o desenvolvimento in vitro dos embriões.

\section{Conclusões}

1. Embriões zigóticos provenientes de frutos imaturos de Jatropha curcas necessitam da suplementação de sacarose no meio de cultura, para sustentar sua germinação, e a adição de sacarose não é necessária para germinação de embriões cotiledonares, provenientes de frutos secos.

2. A associação de carvão ativado e água de coco proporciona melhor crescimento de plântulas oriundas de embriões germinados in vitro provenientes de frutos secos.

3. Raízes das plântulas, obtidas a partir da germinação de embriões zigóticos provenientes de frutos secos, se desenvolvem bem em meio de cultura acrescido de carvão ativado.

\section{Agradecimentos}

À Fundação de Amparo à Pesquisa do Estado de Minas Gerais, pelo apoio financeiro recebido.

\section{Referências}

ARRUDA, F.P.; BELTRÃO, N.E.M.; ANDRADE, A.P.; PEREIRA, W.E.; SEVERINO, L.S. Cultivo de pinhão-manso (Jatropha curcas 
L.) como alternativa para o Semi-Árido nordestino. Revista Brasileira de Oleaginosas e Fibrosas, v.8, p.789-799, 2004.

BOX, G.E.P.; DRAPER, N.R. Empirical model-building and response surfaces. New York: John Willey, 1987. 669p.

CARVALHO, J.M.F.C.; SOUSA JÚNIOR, R.L. de; LOPES, K.P.; SANTOS, J.W. dos. Otimização da metodologia da regeneração de embrião imaturo de algodão. Campina Grande: Embrapa Algodão, 2003. 3p. (Embrapa Algodão. Comunicado técnico, 173)

CHAGAS, E.A.; PASQUAL, M.; RAMOS, J.D.; PIO, L.A.S.; DUTRA, L.F.; CAZETTA, J.O. Cultivo de embriões imaturos de citros em diferentes concentrações de carvão ativado e ácido giberélico. Ciência e Agrotecnologia, v.29, p.1125-1131, 2005.

FERREIRA, M.G.R. das; CÁRDENAS, F.E.N.; CARVALHO, C.H.S. de; CARNEIRO, A.A.C.; DAMIÃO FILHO, C.F.D. Indução de calos embriogênicos em explantes de cupuaçuzeiro. Revista Brasileira de Fruticultura, v.26, p.372-374, 2004.

GARCÍA, J.L.; TRONCOSO, J.; SARMIENTO, R.; TRONCOSO, A. Influence of carbon source and concentration on the in vitro development of olive zygotic embryos and explants raised from them. Plant Cell, Tissue and Organ Culture, v.69, p.95-100, 2002.

GRATTAPAGLIA, D.; MACHADO, M.A. Micropropagação. In: TORRES, A.C.; CALDAS, L.S.; BUSO, J.A. (Ed.). Cultura de tecidos e transformações genéticas de plantas. Brasília: EmbrapaSPI; Embrapa-CNPH, 1998. v.1. p.183-260.

HU, C.Y; FERREIRA, A.G. Cultura de embriões. In: TORRES, A.C.; CALDAS, L.S.; BUSO, J.A. (Ed.). Cultura de tecidos e transformação genética de plantas. Brasília: Embrapa-SPI; Embrapa-CNPH, 1998. v.1. p.371-393.

JESUS, A.M.S.; PASQUAL, M.; DUTRA, L.F.; CHAGAS, E.A. Cultivo in vitro de embriões zigóticos de Jatropha. Revista Ceres, v.50, p.183-189, 2003.

LATADO, R.R.; VAZ, F.B.D.; TULMANN NETO, A. Obtenção de plantas de limão-cravo (Citrus limonia Osbeck) e tangerina 'Cleópatra' (Citrus reshni Hort.) a partir do cultivo de protoplastos de suspensão celular. Scientia Agricola, v.56, p.421-428, 1999.

LEDO, A.S.; GOMES, K.K.P.; BARBOZA, S.B.S.C.; VIEIRA, G.S.S.; TUPINAMBÁ, E.A.; ARAGÃO, W.M. Cultivo in vitro de embriões zigóticos e aclimatação de plântulas de coqueiro-anão. Pesquisa Agropecuária Brasileira, v.42, p.147-154, 2007.
MURASHIGE, T.; SKOOG, F. A revised medium for rapid growth and bioassays with tobacco tissue cultures. Physiologia Plantarum, v.15, p.473- 479, 1962.

PAN, M.J.; STADEN, J.V. The use of charcoal in vitro culture: a review. Plant Growth Regulation, v.26, p.155-163, 1998.

PEREIRA, J.E.S.; MACIEL, T.M.S.; COSTA, F.H. da S.; PEREIRA, M.A.A. Germinação in vitro de embriões zigóticos de murmuru (Astrocaryum ulei). Ciência e Agrotecnologia, v.30, p.251-256, 2006.

PINHEIRO, C.S.R.; MEDEIROS, D.N. de; MACÊDO, E.C. de; ALLOUFA, M.A.I. Germinação in vitro de mangabeira (Hancornia speciosa Gomez) em diferentes meios de cultura. Revista Brasileira de Fruticultura, v.23, p.413-416, 2001.

RIBEIRO, V.G.; SANÁBIO, D.; SOUZA, C.N. de; LOPES, P.S.N.; BOCARDO, M.R.; PASQUAL, M. Efeitos de ácido giberélico e carvão ativado no cultivo in vitro de Citrus limonia Osbeck x Poncirus trifoliata (L.) Raf. Pesquisa Agropecuária Brasileira, v.35, p.2730, 2000 .

RODRIGUES, M.M; MELO, M.D; ALOUFA, M.A.I. Propagação vegetativa in vitro e análise estrutural de macieira. Pesquisa Agropecuária Brasileira, v.41, p.171-173, 2006.

SAS INSTITUTE. SAS: user's guide. Cary: Sas Institute, 1998. 521p. SATURNINO, H.M.; PACHECO, D.D.; KAKIDA, J.; TOMINAGA, N.; GONÇALVES, N.P. Cultura do pinhão-manso (Jatropha curcas L.). Informe Agropecuário, v.26, p.44-74, 2005.

SKREBSKY, E.C.; NICOLOSO, F.T.; FERRÃO, G. da. E. Sacarose e período de cultivo in vitro na aclimatização ex vitro de ginseng brasileiro (Pfaffia glomerata (Spreng.) Pedersen. Ciência Rural, v.34, p.1471-1477, 2004.

SPERA, M.R.N. Propagação in vitro de Jatropha podagrica Hook. 1995. 78p. Dissertação (Mestrado) - Universidade Federal de Lavras, Lavras.

TAPANES, N.O.; ARANDA, D.A.G.; CARNEIRO, J.W. de M. Transesterificação dos glicerídeos do óleo de Jatropha curcas $\mathbf{L}$.: estudo teórico. Disponível em: http://www.biodiesel.gov.br/docs/ congressso2006/producao/Glice27.pdf. Acesso em: 20 dez. 2007

TORRES, A.C.; DUVAL, F.G.; RIBEIRO, D.G.; BARROS, A.F.F.; ARAGÃO, F.A.D. Efeito da sacarose, cinetina, isopentenil adenina e zeatina no desenvolvimento de embriões de Heliconia rostrata in vitro. Horticultura Brasileira, v.23, p.789-792, 2005. 